\title{
APPLICATION OF REMOTE SENSING TECHNIQUES ON ASTER DATA FOR ALTERATION ZONES EXTRACTION AND LITHOLOGICAL MAPPING OF EL- FAWAKHIR - EL-SID AREA, CENTRAL EASTERN DESERT, EGYPT: AN APPROACH FOR GOLD EXPLORATION
}

\author{
Ghoneim, S. M. ${ }^{1}$, Salem, S. M. ${ }^{1}$ and El-Sharkawi, M. A. ${ }^{2}$ \\ 1 The National Authority for Remote Sensing and Space Sciences (NARSS). \\ 2 Geology Department, Cairo University.
}

\begin{abstract}
Remote sensing images are widely used in many geological applications; in our research we used remote sensing techniques for lithological mapping and mineral exploration through extracting the alteration zones with integration of lineaments density in the study area.

For lithological mapping; False Color Composite (FCC), Color Ratio Composites (CRC) and Principal Component Analysis (PCA) techniques were used. To extract the alteration zones; Spectral ratio indices, Constrained Energy Minimization (CEM) and spectral signature based supervised classification techniques named Spectral Angle Mapper (SAM) and Spectral Information Divergence (SID) have been applied on ASTER data. At last, the final alteration map is integrated with lineament density map and the locations of the old gold mines in the area for introducing the probable potential areas for gold exploration.
\end{abstract}

Keywords: El-Fawakhir, El-Sid, Gold, ASTER and Remote Sensing.

\section{INTRODUCTION}

Gold mineralization is widely distributed in the Arabo-Nubian Shield and its genesis is discussed in several works (Garson and Shalaby, 1976; EI-Gaby et al, 1988). Most of these Au deposits are hosted by intrusives, volcanics, ophiolitic rocks and post-orogenic granites.More than 95 gold occurrences are known in the Eastern Desert of Egypt, these are reviewed by Hume (1937), El Ramly et al., (1970) and Sabet et al., (1976). They have been discovered, explored, and/or mined since the Pharaonic time. Gold deposits of the Arabian-Nubian Shield have for a long time been an important association and promises to continue to be important (Abdelsalam et al., 2000).

Traditionally, lithological mapping and mineral exploration has depended on several prospecting techniques including geochemistry, geophysics, geological mapping, interpretation of aerial photos and ground surveys (Chica-Olmo et al., 2002). Lithological units and structural features represent significant data sources for mineral exploration (Brandmeier, 2010).

Recently, satellite images have been widely used successfullyfor geological applications including lithological mapping and delineating alteration zones which contain minerals and ore deposits of economic potential. Salem (2013) used remote sensing techniques for detecting gold in listwanite alteration at Barramiya area, the southern extension of the study area. Abou El-Magd et al., (2015) used ASTER data for gold exploration in El-Sid area. In the present study, lithological mapping, alterations mapping, lineament detection were performed on ASTER data to define the alteration zones for gold deposits. Several remote sensing techniques including False Color Composite (FCC), Color Ratio Composites (CRC) and Principal Component Analysis (PCA), Spectral ratio indices, Constrained Energy Minimization (CEM) and spectral signature based supervised classification techniques named Spectral Angle Mapper (SAM) and Spectral Information Divergence (SID) along with automatic lineament extraction technique have been applied on ASTER data. 


\section{STUDY AREA}

The study area (Fig.1) is located about $88 \mathrm{Km}$ west of the Red Sea coast, along the Qift-Quseir highway in the Eastern Desert of Egypt. The area lies between latitudes $25^{\circ} 56^{\prime} 20^{\prime \prime}-26^{\circ} 03^{\prime} 40 " \mathrm{~N}$ and longitudes $33^{\circ} 30^{\prime} 30^{\prime \prime}-33^{\circ} 40^{\prime} 30^{\prime \prime} \mathrm{E}$.

Fig.1: Location map of the study area.

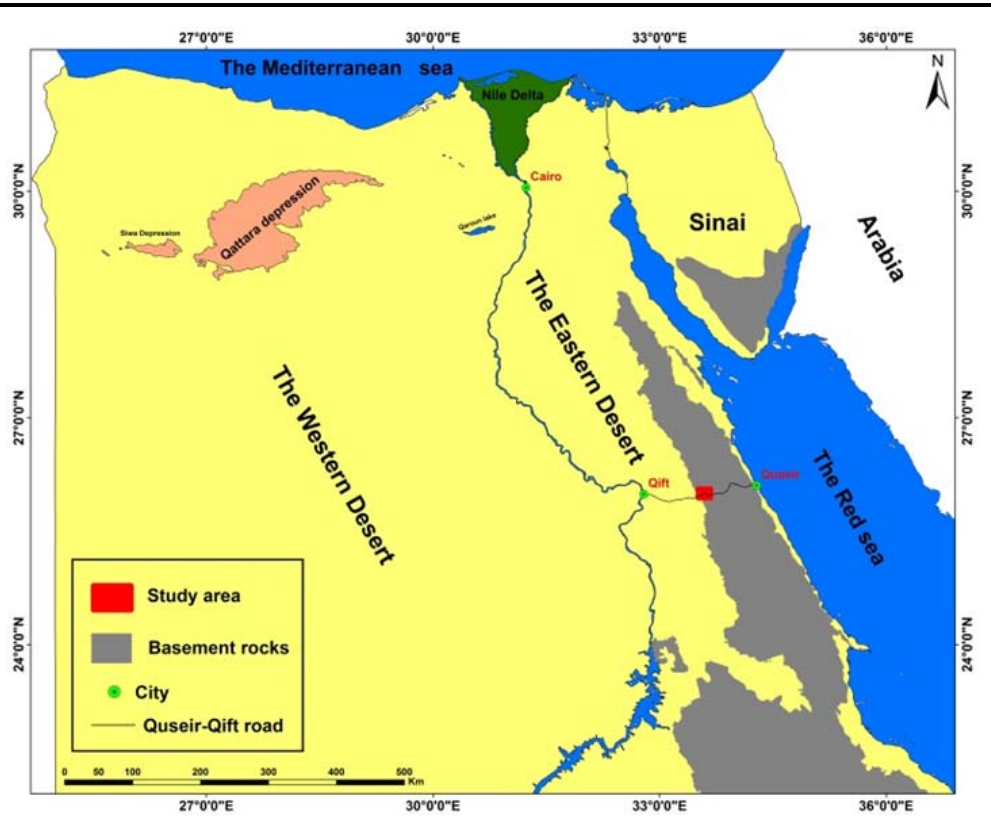

GEOLOGICAL SETTING

The area includes ophiolitic rocks, Hammamat molasse sediments, Dokhan Volcanics, felsites, older and younger pink granites (Fig. 2). The ophiolitic rocks are composed of ultramafic rocks (serpentinite), mafic plutonic rocks (metagabbro), and metavolcanics (metabasalt) (El-Sayed et al., 1999) and they are intruded by the younger granite of the fawakhir pluton. The contacts between the serpentinites and the adjacent rocks are sharp, distinct and marked by a deep thrust fault trending N-NW (Harraz and Ashmawy 1994). Metagabbros constitute a major part of the Fawakhir ophiolite suite and have suffered regional metamorphism up to greenschist facies (El-Sayed et al., 1999). Hammamat molasses sediments occupy almost the western part of the study area, the Hammamat sediments are found to be intruded by the younger granites of the Um Had pluton at the northwestern part of the study area.

\section{DATA AND METHODS}

ASTER level 1b image acquired by the joint American-Japanese satellite on board Terra platformon 7th, October2007, was used in this study. Different processing techniques have been carried to achieve the aim of the study.

\section{Pre-processing of the ASTER data}

Most satellite images are in the form of digital data. Digital image is therefore stored on a series of digital numbers (DNs), Digital numbers (DNs) range from 0 to 255 in the gray-scale intensity values (Sabins, 1997).Therefore, because the image in the digital format exists as a simple array of numbers within the computer, various mathematical procedures were performed to make the data more usable for further processing techniques. 


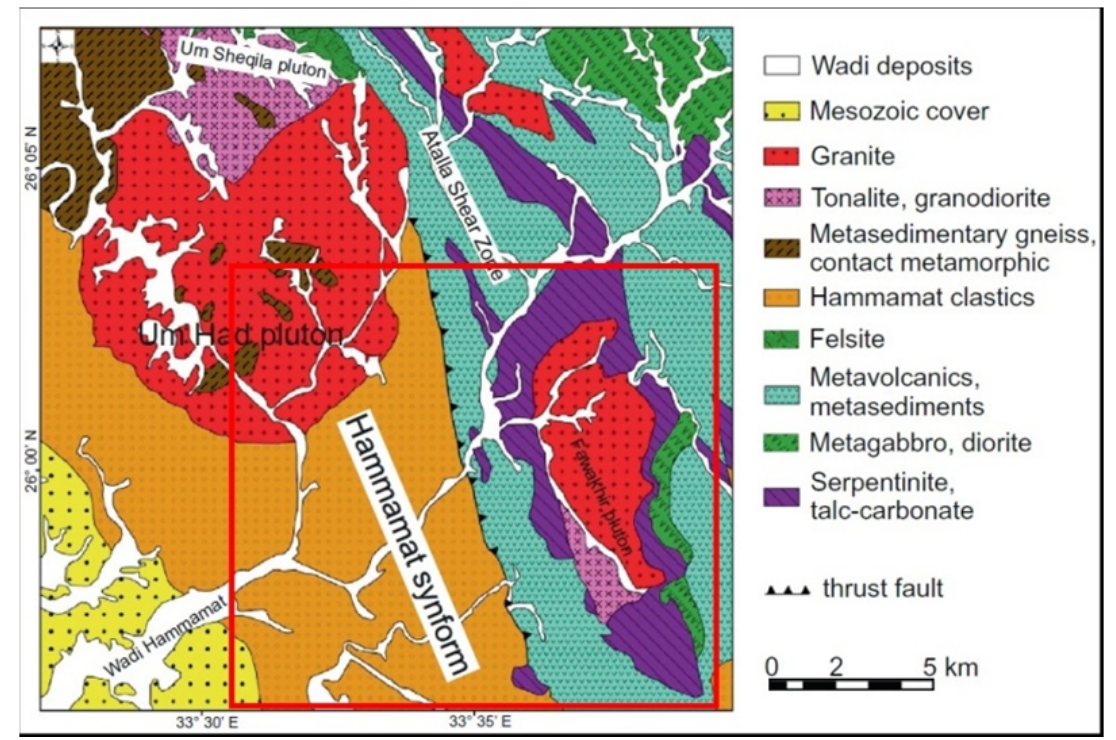

Fig. 2: Geological map of the study area (bounded by the red frame) (after Greiling et al 2014).

\section{Geometric Projection (Georeferencing) of the data}

This function was used to ensure that the satellite image is rectified to the actual coordinates on the ground; consequently, all the spatial and the geographic data will be correctly overlain and fit the ground coordinates. Fortunately, ASTER level $1 \mathrm{~b}$ data is provided geometrically registered, but the scene is pathoriented and deviated from the north about 9 degrees to the east, so, it needs to be rectified to fit the north in a process called northing up

\section{(https://lpdaac.usgs.gov/sites/default/files/public/aster/docs/ASTER_GeoRef_FINAL.pdf).}

\section{Cross talk correction}

A cross talk signal scattering problem inthe SWIR sensor of the ASTER data is common, the light incident to band 4 and band 9 is reflected at the detector and the filter boundary then, transported to other bands by multiple reflections in the focal area. A crosstalk correction algorithm is developed to improve the spectral separation performance of SWIR.

\section{Calibration from digital numbers to spectral radiance then to spectral reflectance}

The raw satellite data comes as digital numbers assigned to each pixel in the image, these digital numbers are converted to spectral radiance, the spectral radiance is then converted to spectral reflectance, such conversion processes is carried out through a set of complicated mathematical equations.Thanks to ENVI software, we managed to convert DNs to spectral reflectance with no need to perform the mathematics manually.

\section{Atmospheric correction of the data}

This processes is very important as it involves converting the top of atmosphere (TOA) reflectance to the surface reflectance by removing the atmospheric actions that cause errors in the spectral reflectance of objects due to the interaction of the incident and reflected energy through the atmosphere with the atmospheric gases such as $\mathrm{CO}_{2}$ and water vapour, also dust particles causesuch atmospheric problems, so, atmospheric correction was performed using the FLAASH module of ENVI v.5.1 to ensure pure surface reflectance for accurate processing.

\section{Spatial resolution merge}

The spatial resolution is the pixel size (the smallest unit in the image). The ASTER subsystems (VNIR, SWIR and TIR) have different spatial resolutions, the VNIR subsystem is $15 \mathrm{~m}$, the SWIR subsystem is $30 \mathrm{~m}$ and the TIR subsystem is $90 \mathrm{~m}$. The resolution merge function was used to merge the higher 
Ghoneim, et al.

resolution data (VNIR 15m) with the lower resolution data (SWIR) to obtain higher spatial resolution for the SWIR data.As a result of using this function we got the SWIR data $15 \mathrm{~m}$ instead of $30 \mathrm{~m}$.

\section{Area of interest}

Since the ASTER scene is larger than the area of interest as, one ASTER scene covers $(60 \mathrm{Km} * 60$ $\mathrm{Km}$ ), the subset function was used to trim out the undesirable areas from the scene and leave only the area needed for the study to make it easy and fast for further processing and to reduce the volume of the resulting on the hard disk of the computer.

\section{Processing techniques applied to the ASTER data}

After performing the pre-mentioned preprocessing steps, the ASTER data is now ready for the image processing techniques available for achieving the purpose of our study. Band selection techniques for selecting the best band triplets for false color composites (FCC), Color Ratio Composites (CRC), Principal Component Analysis (PCA), Constrained Energy Minimization (CEM), spectral ratio indices and the signature based supervised classification techniques named Spectral Angle Mapper (SAM) and Spectral Information Divergence (SID) techniques, these techniques were integrated along with the automatic lineament extraction from the ASTER imagery which have been used as well.

\section{RESULTS}

\section{Bands Selection for False Color Composite (FCC) images}

A particular aspect of remote sensing is that it provides data in multiple spectral bands. ASTER data contain fourteen spectral bands. To display a FCC image only three bands are required in a band combination, each directed to one of the three color-guns; Red, Green and Blue (RGB). So, we have a wide range of possible triplet band combinations, we used formula (1) retrieved from (mathforum.org/library/drmath/view/59185.html) to calculate the number of possible band combinations from the nine bands of the VNIR-SWIR ASTER data.

$$
\text { Band triplets }\left(\begin{array}{l}
N \\
3
\end{array}\right)=\frac{N !}{(3 ! *(N-3) !)} \quad \text { Formula (1) }
$$

Where, $\mathrm{N}$ is the total number of bands, for the nine bands of the ASTER VNIR-SWIR subsystems, there are 84 possible combinations.

Selection of appropriate band triplets for the False Color Composite (FCC) images was performed in two different ways; the correlation coefficient method and the Optimum Index Factor (OIF) method. The less correlated bands are good for image visualization in RGB color space (Drury, 1993).

\section{Correlation coefficientmethod}

The correlation coefficient is a statistical method that is used to determine the strength of the linear relationship between variables. The smaller the correlation coefficient, the larger the variance in the data and vice versa. The correlation matrix of the nine VNIR-SWIR bands is presented in Table (1).

Table1:CorrelationcoefficientofASTERVNIR-SWIRdataofthestudy area.

\begin{tabular}{|l|l|l|l|l|l|l|l|l|l|} 
& B1 & B2 & B3 & B4 & B5 & B6 & B7 & B8 & B9 \\
\hline B1 & 1 & & & & & & & & \\
\hline B2 & 0.996 & 1 & & & & & & & \\
\hline B3 & 0.993 & 0.998 & 1 & & & & & & \\
\hline B4 & 0.971 & 0.977 & 0.981 & 1 & & & & & \\
\hline B5 & 0.981 & 0.984 & 0.987 & 0.990 & 1 & & & & \\
\hline B6 & 0.977 & 0.982 & 0.984 & 0.983 & 0.992 & 1 & & & \\
\hline B7 & 0.953 & 0.958 & 0.961 & 0.976 & 0.969 & 0.963 & 1 & & \\
\hline B8 & 0.958 & 0.964 & 0.968 & 0.982 & 0.975 & 0.969 & 0.993 & 1 & \\
\hline B9 & 0.971 & 0.974 & 0.976 & 0.988 & 0.983 & 0.976 & 0.985 & 0.991 & 1 \\
\hline
\end{tabular}


Application of remote sensing techniques on aster data

From the results of the Correlation Coefficient method, a positive correlation has been observed between the nine ASTER VNIR-SWIR bands (Tables1\&2).But bands 1, 2, 7 and 8 are relatively fewer correlations with the other reflective bands.T he best ten band triplet possibilities are given in Table (2) in descending order.

Table 2: Correlation coefficient method ranking of the best band triplet selection of the ASTER data of the study area.

\begin{tabular}{|c|c|c|}
\hline Band Triplet & Correlation coefficient & Rank \\
\hline $1,6,7$ & 2.892882 & 1 \\
\hline $1,4,7$ & 2.899963 & 2 \\
\hline $1,5,7$ & 2.902785 & 3 \\
\hline $1,7,8$ & 2.903216 & 4 \\
\hline $2,6,7$ & 2.903290 & 5 \\
\hline $1,6,8$ & 2.903799 & 6 \\
\hline $1,3,7$ & 2.906087 & 7 \\
\hline $1,2,7$ & 2.906341 & 8 \\
\hline $1,7,9$ & 2.908068 & 9 \\
\hline $3,6,7$ & 2.908123 & 10 \\
\hline
\end{tabular}

\section{Optimum Index Factor (OIF)}

OIF is a statistic calculation of every possible three-bands rendered as R-G-B. It is developed by Chavez et al (1982 \& 1984). The OIF technique was applied to ASTER VNIR-SWIR nine bands. The best ten band triplet possibilities were ranked indescending order (Table 3). The higher the OIF values, the more the information content. So, triplets with higher values of OIF were used for better extraction of lithological information since they use bands with highest variance and least redundancy (Qaid and Basavarajappa, 2008).

Table 3: OIF rankingof VNIR-SWIR data of the studyarea.

\begin{tabular}{|c|c|c|}
\hline Band Triplet & OIF & Rank \\
\hline $1,2,3$ & 47.94864204 & 1 \\
\hline $1,2,4$ & 38.77910803 & 2 \\
\hline $1,2,7$ & 36.59802721 & 3 \\
\hline $1,2,8$ & 36.15756466 & 4 \\
\hline $1,2,5$ & 36.08277367 & 5 \\
\hline $1,2,6$ & 36.07930166 & 6 \\
\hline $1,2,9$ & 35.64442541 & 7 \\
\hline $1,3,4$ & 35.21589781 & 8 \\
\hline $2,3,4$ & 33.76479559 & 9 \\
\hline $1,3,7$ & 33.00345688 & 10 \\
\hline
\end{tabular}

The analysis of the highest band-triplet ranks obtained from both the methods yielded that, only $(7,2$ and 1) and (7, 3 and 1) band triplets were in the best ten ranks of both the two used methods, while the other eight band triplets are different in one method than that in the other one. Bands 1 and 2 are almost in allthe band triplets obtained from the optimum index factor method, while, in the correlation coefficients method there are better representation of almost all the ASTER VNIR-SWIR bands. So, the correlation coefficients method is better than the optimum index factor method in this study.

Visual inspection yielded that the RGB false color composite images (7, 6 and 1) from the correlation coefficient method, (4, 2 and 1) from the OIF method and (7, 3 and 1) from both methods; are the best for extracting the lithological information (Figs. 3a, b \&c).

\section{Band ratio: Color Ratio Composites (CRC)}

Ratio images are obtained by dividing the DN in one band by the corresponding DN in another band for each pixel, stretching the resulting value, and plotting the new value as an image (Sabins, 1997). Rationing is an effective method for distinguishing among rock types because it removes first-order brightness effects due to topographic slopes and enhances subtle color variations between materials 
Ghoneim, et al.

(Abrams et al., 1983). Band ratio images are used to suppress the topographic variation, and the brightness difference related to grain size variation (Sultan and Arvidson, 1986).

In the present study, two color ratio composites were tested and found to be the best composites for discriminating the lithological units and alteration zones. The first one is (4/7, 3/4 and 2/1) for RGB respectively (Fig. 4a), this ratio is equivalent to Abram's ratio (5/7, 4/5, 3/1) of Landsat TM (Abrams et al., 1983) which was used by Abdeen et al., (2001) for mapping serpentinite, granite and marble units of the Neoproterozoic Allaqi Suture in southern Eastern Desert of Egypt. The second ratio is (4/7, 4/1and $2 / 3 * 4 / 3$ ) for RGB respectively (Fig. 4b), which ratio is equivalent to Sultan's ratio (5/7, 5/1, 3/4 * 5/4) of Landsat TM (Sultan and Arvidson, 1986).

The rock units that are successfullymapped using these ratios include serpentinite, granite, Hammamat molasse sediments, felsite, metagabbro, Dokhan Volcanics and melange rocks. For validation of the adopted ASTER band-ratios images, Principal component analysis (PCA) technique is used.

\section{Principal Component Analysis (PCA)}

PCA is a statistical technique used to reduce the redundancy between the spectral reflectance of the bands.Multispectral image bands are often highly correlated, i.e., they are visually and numerically similar (Schowengerdt, 2007). Important geologic information might occupy only a small portion of the spectral range of one band that is otherwise highly correlated with other bands; it is possible that such information will be lost through one of these other bands being chosen instead.

Fig. 3a: ASTER FCC image 7, 6 and 1 in (RGB) respectively.
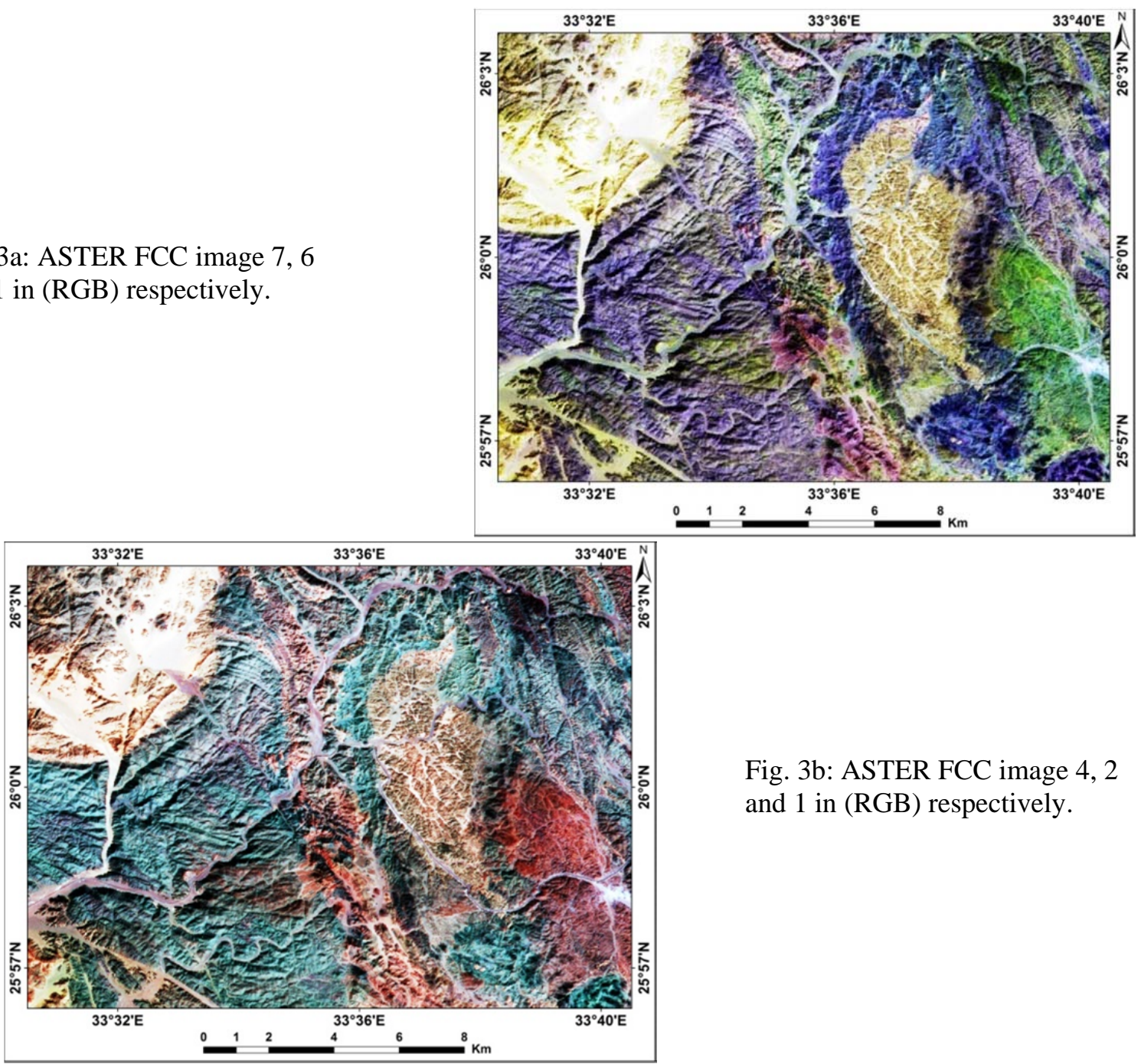

Fig. 3b: ASTER FCC image 4, 2 and 1 in (RGB) respectively. 
Application of remote sensing techniques on aster data

Fig. 3c: ASTER FCC image 7, 3 and 1 in (RGB) respectively.
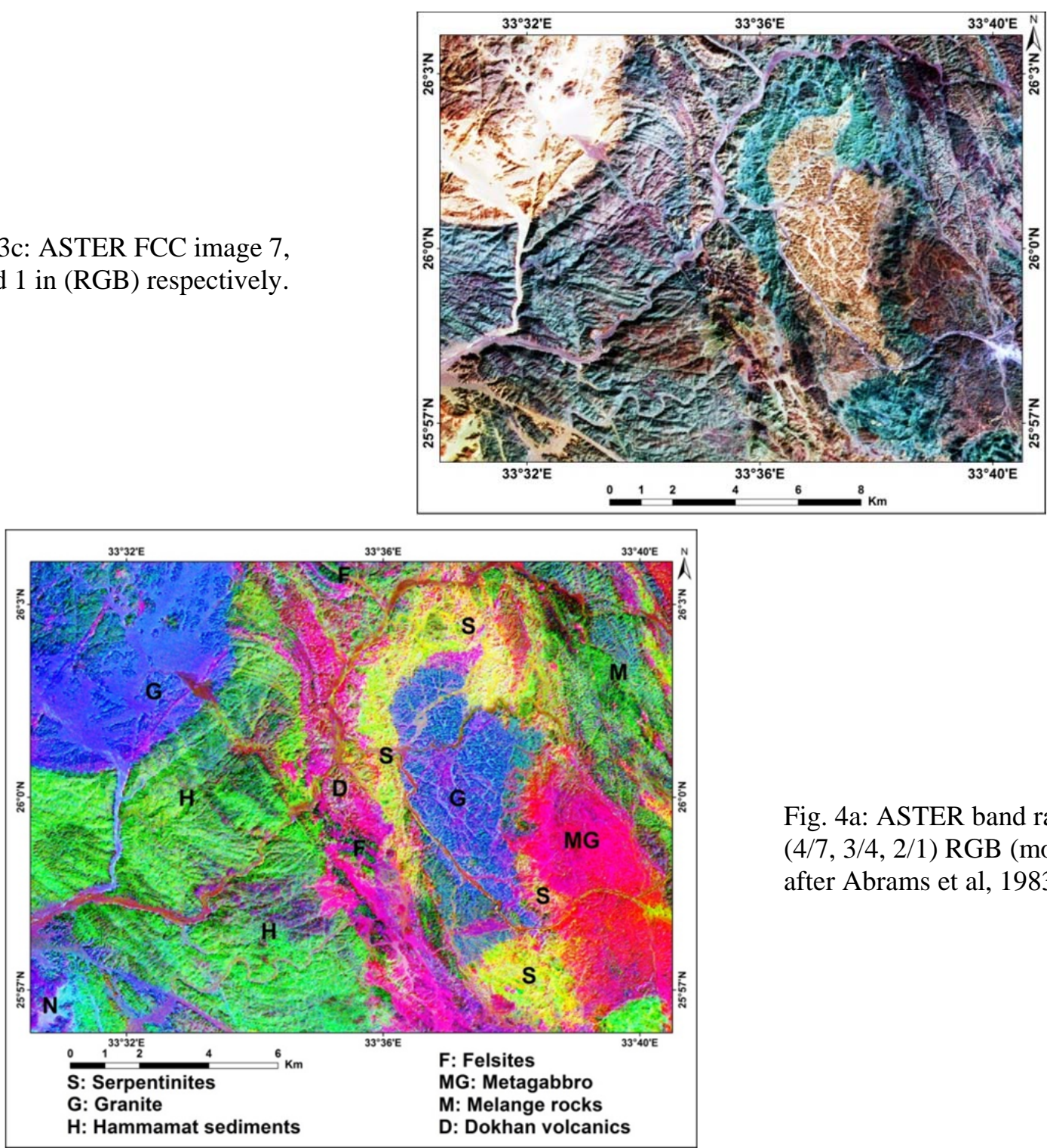

Fig. 4a: ASTER band ratio (4/7, 3/4, 2/1) RGB (modified after Abrams et al, 1983).

Fig.4b: ASTER band ratio $(4 / 7,4 / 1,2 / 3 * 4 / 3)$ RGB (modified after Sultan et al, 1986).

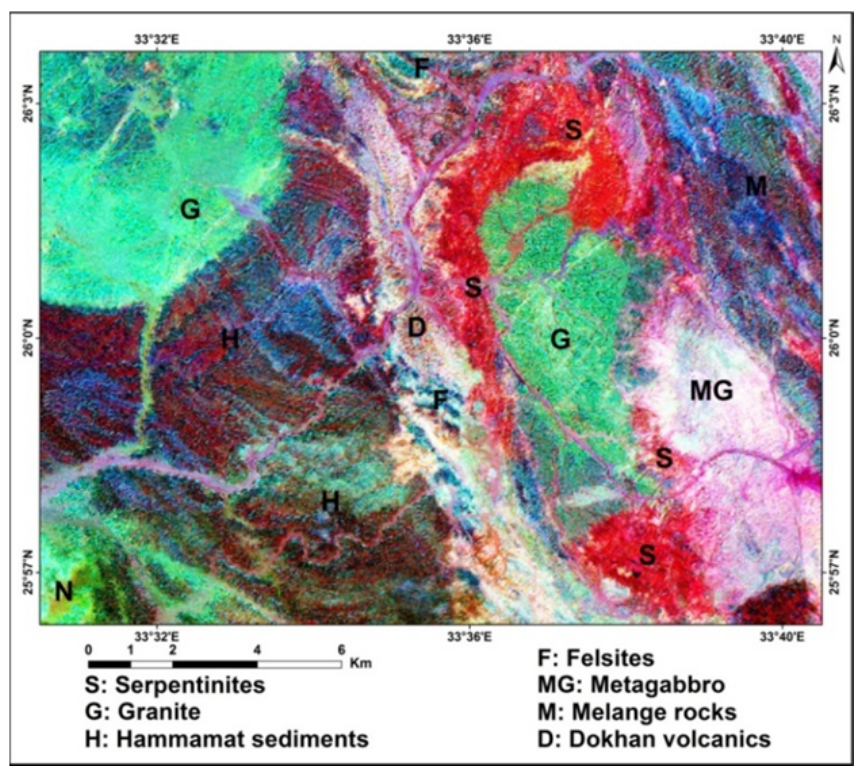


Ghoneim, et al.

In Principal Component Analysis most of the variance in multispectral data is compressed into almost three or four principal component images while, noise may be accumulated in less correlated principal component images (Abou El-Magd et al., 2015).

The first PC image contains data with highest variance and least correlation, unlike, the last PC image which contains data with least variance and high correlation and appears noisy and one cannot define it's features (Figs. 5a \& 5b).

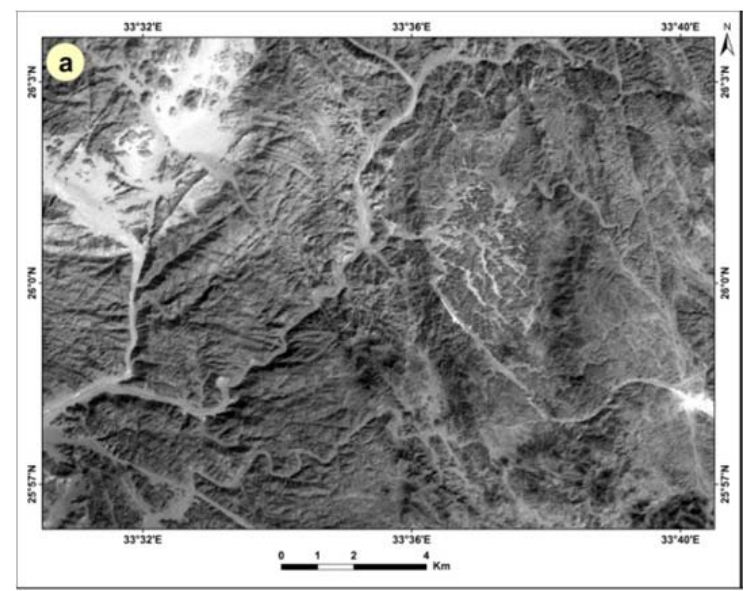

Fig. 5a: the first principal component image (PC1), the image features are clear.

Fig. 5b:The last principal component image (PC9), the image appears noisy and the features are not clear.

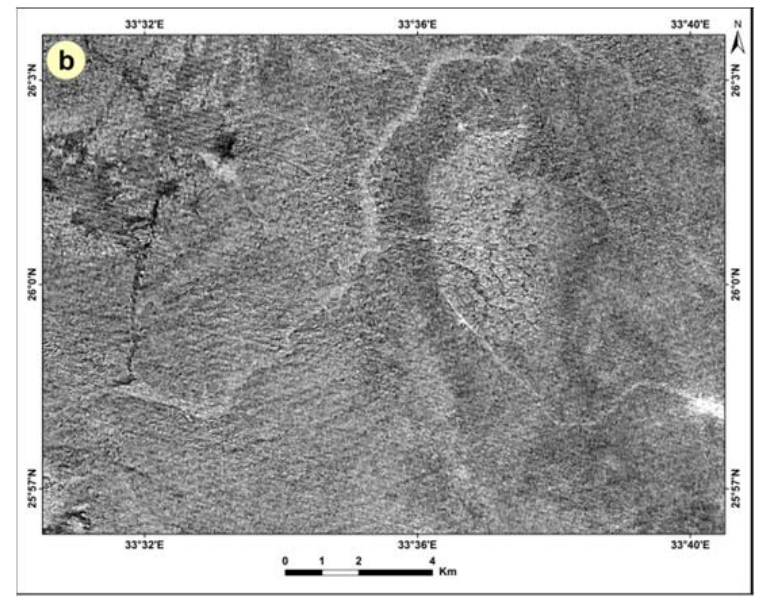

From the analysis of the eigenvector matrix (Table 4) of the ASTER VNIR-SWIR data, PC1, 2, 3and 4 contains $99.181 \%$ of the information content of the data while the other PC bands contains only $0.819 \%$. PCA color composites PC3, PC2 and PC1 (Fig. 6a) and PC4, PC2 and PC1 (Fig. 6b) were used as they contain the most informative data with maximum variance and helped in delineating the contacts between the rock units in the study area.

Table 4: Eigenvector matrix and loadings of principal component analysis on ASTER.

\begin{tabular}{|c|c|c|c|c|c|c|c|c|c|c|}
\hline & & PC1 & PC2 & PC3 & PC4 & PC5 & PC6 & PC7 & PC8 & PC9 \\
\hline \multirow{3}{*}{ 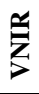 } & Band1 & 0.985 & 0.170 & 0.005 & -0.006 & -0.003 & 0.008 & -0.0003 & 0.001 & 0.001 \\
\hline & Band2 & -0.170 & 0.984 & 0.030 & 0.031 & 0.011 & -0.009 & 0.004 & 0.0006 & -0.0009 \\
\hline & Band3 & 0.0001 & -0.030 & 1.000 & -0.006 & -0.002 & 0.007 & 0.0001 & 0.001 & 0.001 \\
\hline \multirow{6}{*}{$\sum_{\infty}^{\mathfrak{s}}$} & Band4 & -0.011 & 0.029 & -0.005 & -0.999 & 0.013 & -0.020 & 0.003 & -0.002 & -0.002 \\
\hline & Band5 & 0.001 & -0.007 & -0.0008 & 0.005 & 0.949 & 0.314 & -0.002 & 0.003 & 0.003 \\
\hline & Band6 & -0.010 & 0.011 & -0.007 & -0.023 & -0.314 & 0.949 & 0.015 & 0.0004 & -0.003 \\
\hline & Band7 & 0.001 & -0.004 & -0.0001 & 0.003 & 0.006 & -0.013 & 1.000 & 0.009 & 0.004 \\
\hline & Band8 & 0.001 & 0.0006 & 0.001 & 0.002 & 0.002 & 0.001 & 0.009 & -1.000 & -0.001 \\
\hline & Band9 & -0.002 & 0.0008 & -0.001 & -0.003 & -0.004 & 0.002 & -0.004 & -0.001 & 1.000 \\
\hline \multicolumn{2}{|c|}{ Eigenvalue } & 136.06 & 8.77 & 2.06 & 1.01 & 0.36 & 0.35 & 0.21 & 0.18 & 0.12 \\
\hline \multicolumn{2}{|c|}{ Information \% } & 91.242 & 5.881 & 1.381 & 0.677 & 0.241 & 0.235 & 0.141 & 0.121 & 0.081 \\
\hline \multicolumn{2}{|c|}{ Sum of Information \% } & \multicolumn{9}{|c|}{$100 \%$} \\
\hline
\end{tabular}


Application of remote sensing techniques on aster data

The results of false color composites (FCC), color ratio composites (CRC) and principal component analysis (PCA) techniques have been integrated and have shown significant identification of lithological units in the studied area (Fig. 7a), resulting in the remote sensing based geological map (Fig. 7b).

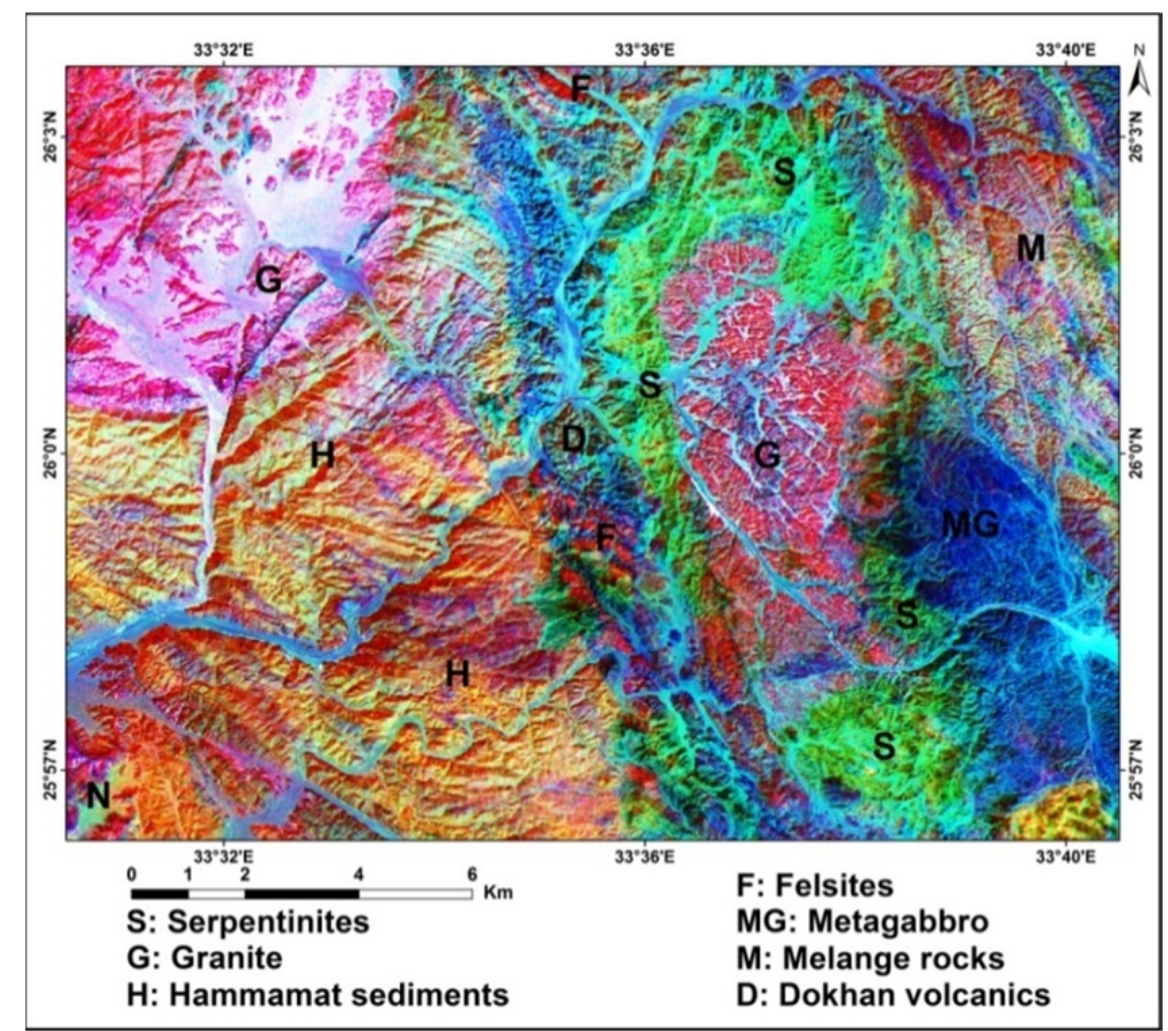

Fig. 6a: ASTER false color composite (PC3, PC2, and PC1) in RGB respectively

Fig. 6b ASTER false color composite (PC4, PC2, and PC1) in RGB respectively

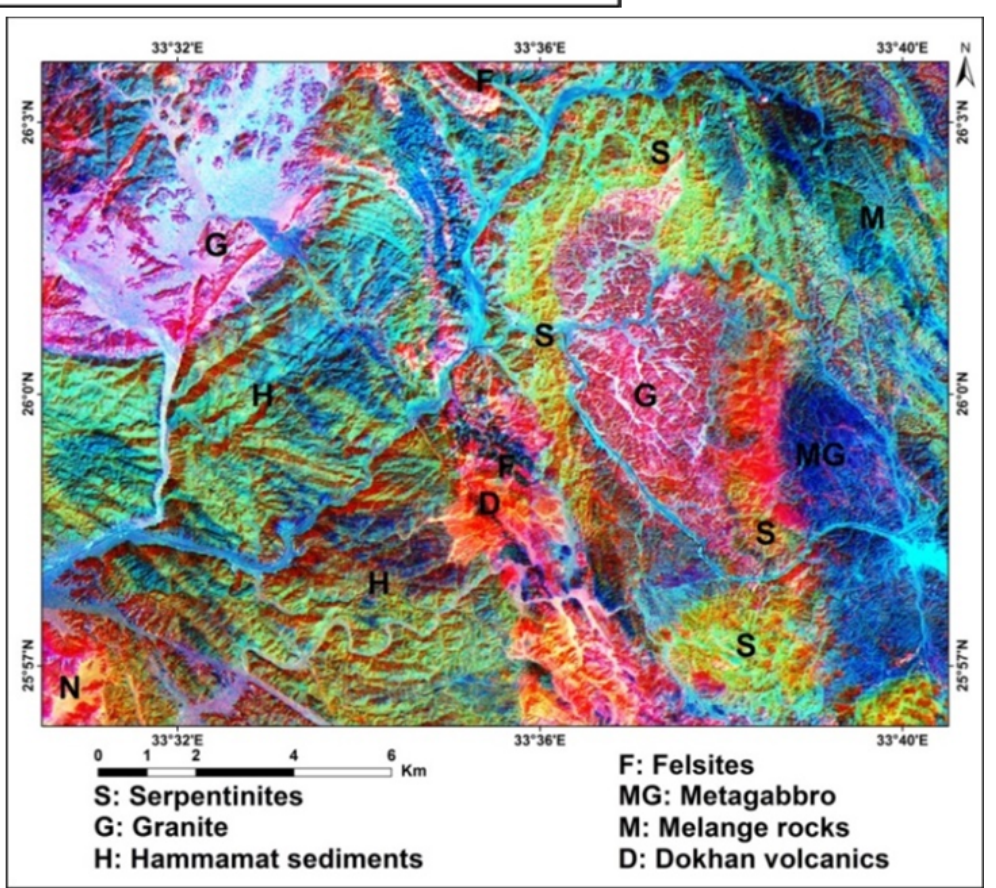

\section{Extracting the alteration zones using ASTER data}

Several remote sensing techniques have been integrated to extract the alteration zones in the study area from the ASTER data, the used techniques are the following: 
Ghoneim, et al.

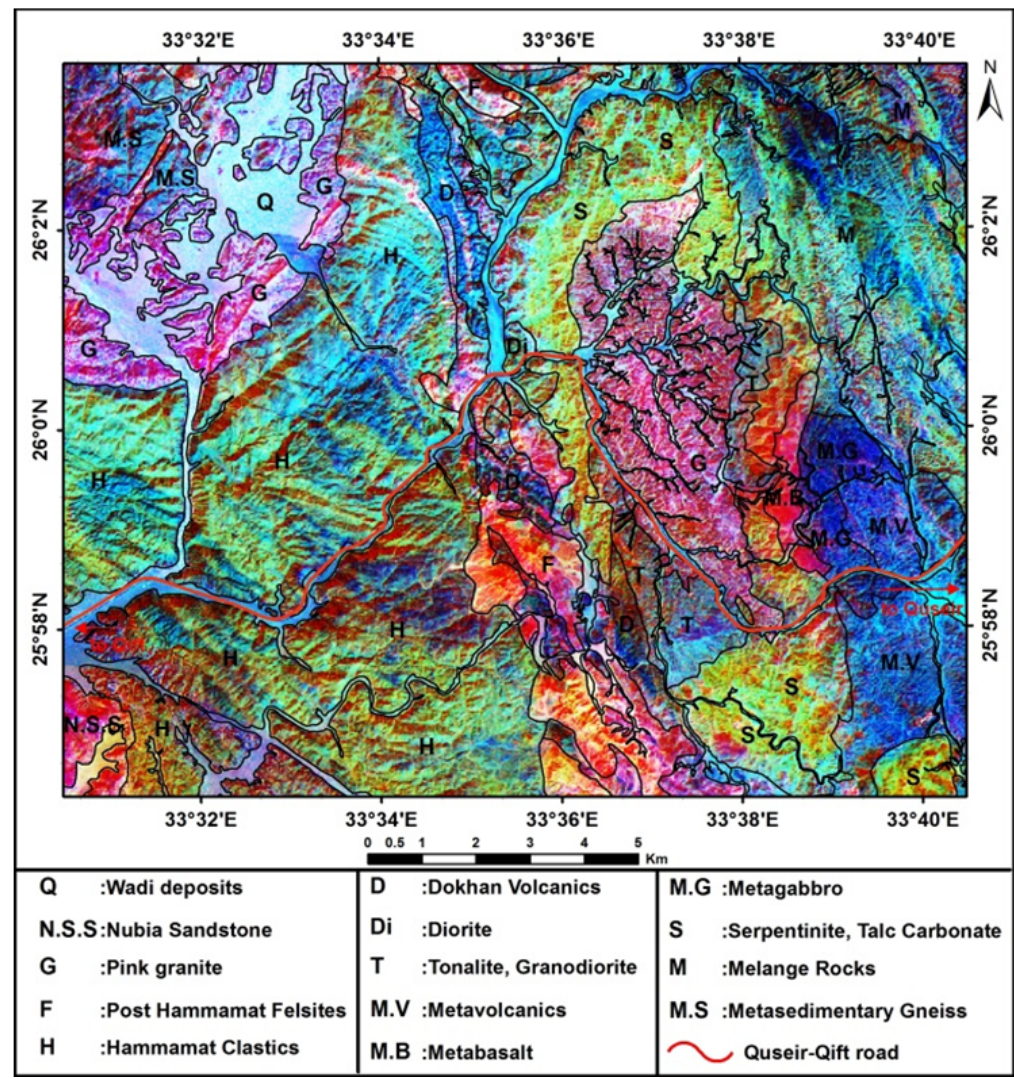

Fig. 7a: ASTER false color composite (PC4, PC2, and PC1) RGB image overlain by the lithological boundaries.

Fig. 7b: Remote sensing based Lithological map of the study area (Final result).

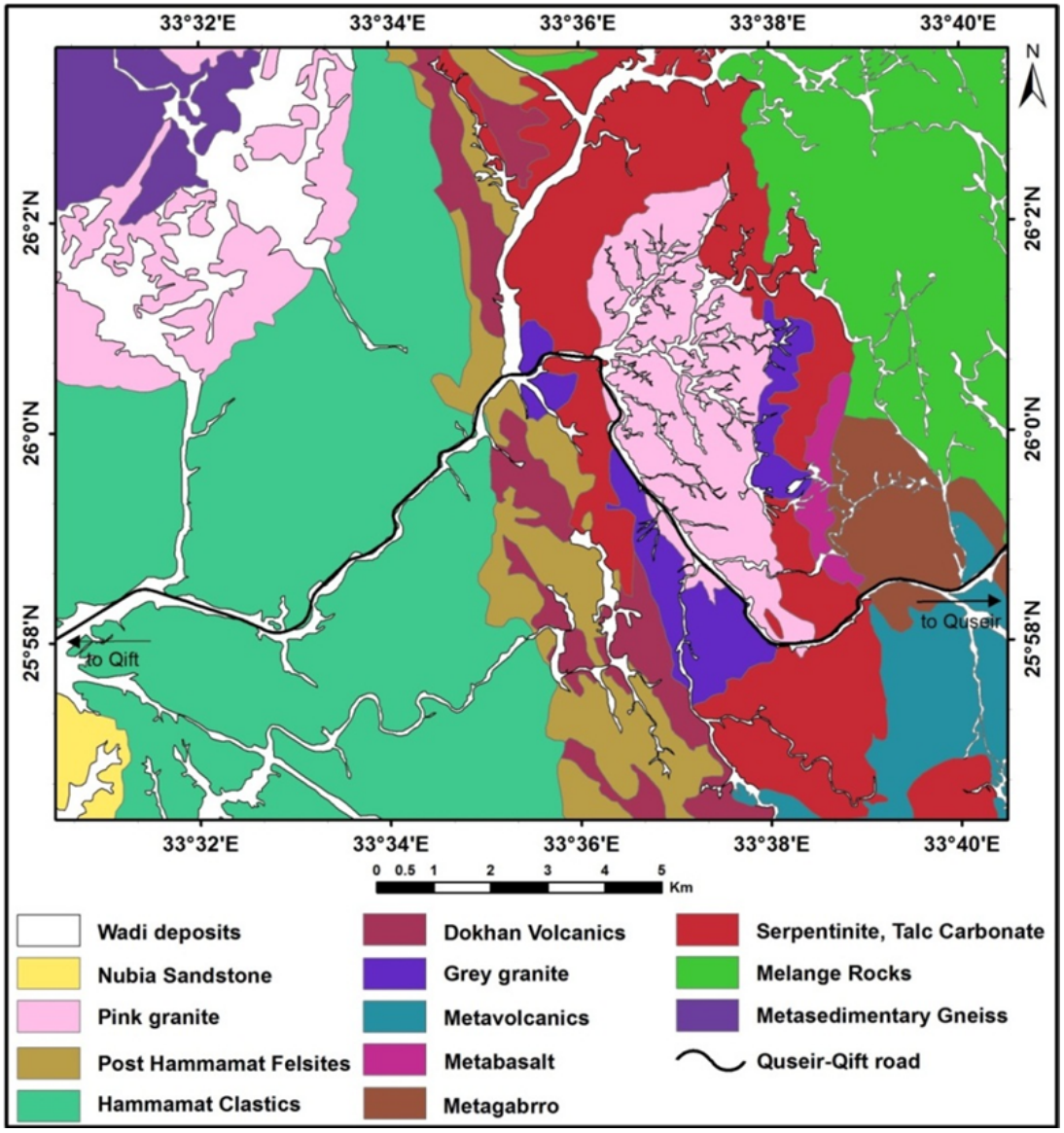


Application of remote sensing techniques on aster data

\section{Band ratios and spectral ratio indices}

Band ratios and spectral ratio indices proved to be very useful for qualitative detection of hydrothermal alteration minerals. This technique has been widely used in geological mapping by different authors (Gad and Kusky, 2007; Amer et al, 2010; Abou El-Magd et al, 2014).

Furthermore, the mineralogical spectral ratio indices proposed by Ninomiya (2003) we used for identifying alteration zones, the formulas of the indices are:

- $\quad$ OHI $=($ band7/band6)*(band4/band6)

- $\quad \mathrm{KLI}=($ band4/band5)*(band8/band6)

- $\quad$ CLI = (band6/band8)*(band9/band8)

Where $\mathrm{OHI}$ is $\mathrm{OH}$-bearing mineral index, KLI is kaolinite index, CLI is calcite index. These minerals are common in hydrothermal alteration zones; they can be used as a sign to define where exactly hydrothermal alterations are and define its spatial distribution. The spectral ratio indices are overlain one on another on ASTER SWIR band 6 (Fig. 8).

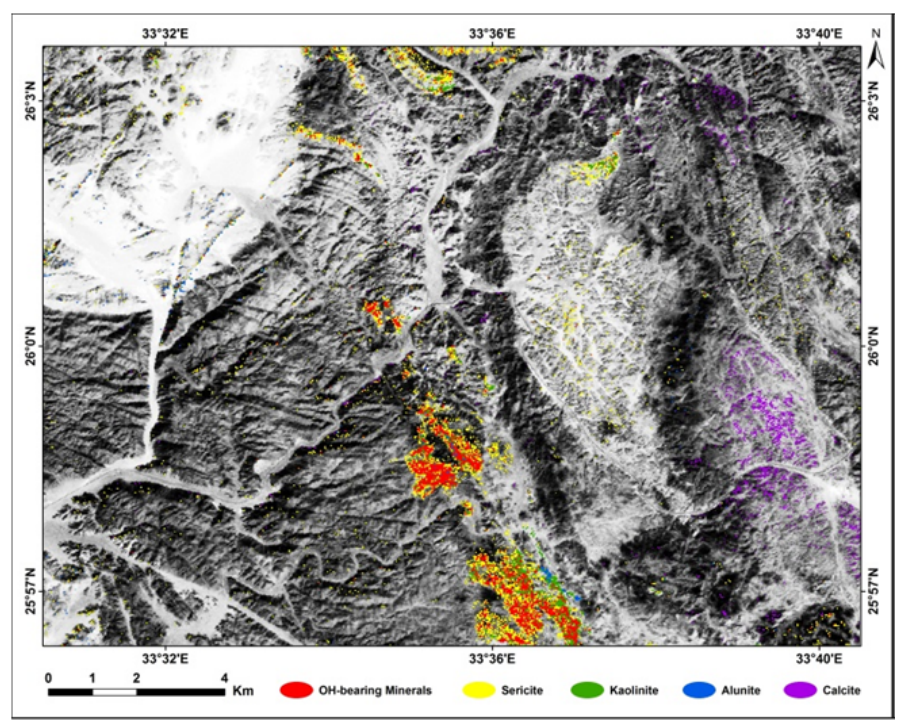

Fig. 8: Alteration zone mapping using spectral ratio indices overlain on ASTER band 6.

\section{Constrained Energy Minimization (CEM)}

The CEM algorithm attempts to maximize the spectrum response of a target and suppress the response of all the other features and consider them as the unknown background. It enabled to identify six alteration minerals which are the main alteration minerals in the rock units of the study area as proved by the microscopic studies by Mohy, 2014, these alteration minerals are alunite, kaolinite, sericite, chlorite, calcite and montmorillonite from the ASTER VNIR-SWIR surface reflectance data. The spectral signatures of these six alteration minerals were derived from the United States Geological Survey (USGS) spectral library (Fig. 9a) embedded in the ENVI software, after being resampled to match the wavelength range of ASTER VNIR-SWIR spectral bands (Fig. 9b). This technique resulted in the abundance of these six alteration minerals in the satellite image (Fig. 10).

The abundance image shows that the distribution of these alteration minerals is highly correlated with the alteration zones extracted from the mineralogical spectral ratio indices method (Fig. 8). The result of the alteration minerals resulted using CEM technique was found to be more sharp and clearer to interpret than the image produced by the mineralogical spectral ratio indices method. However, the CEM technique did not perform well in conditions where the background signature is not easily detected, therefore, fails to identify rare minerals (e.g. secondary iron-rich parts of the alteration) that are not spatially dominant in the satellite image (Gabr et al., 2010). 
Ghoneim, et al.

Fig. 9a: USGS

typical spectral signatures of the alteration minerals (montmorillonite, sericite, kaolinite, alunite, calcite and chlorite).
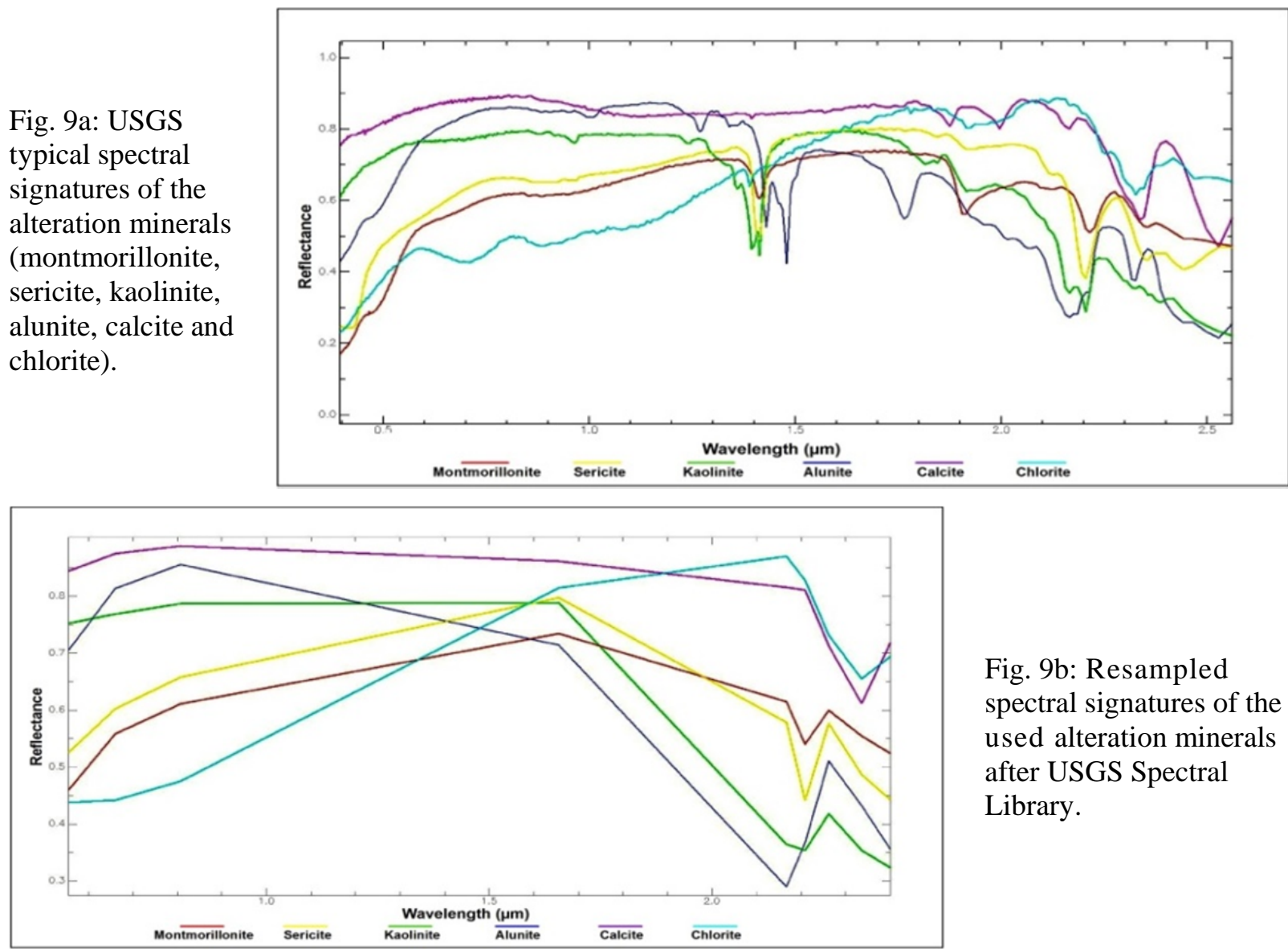

Fig. 9b: Resampled spectral signatures of the used alteration minerals after USGS Spectral Library.

Fig. 10: Alteration minerals

abundance image usingthe CEM technique overlying ASTER band 6 .

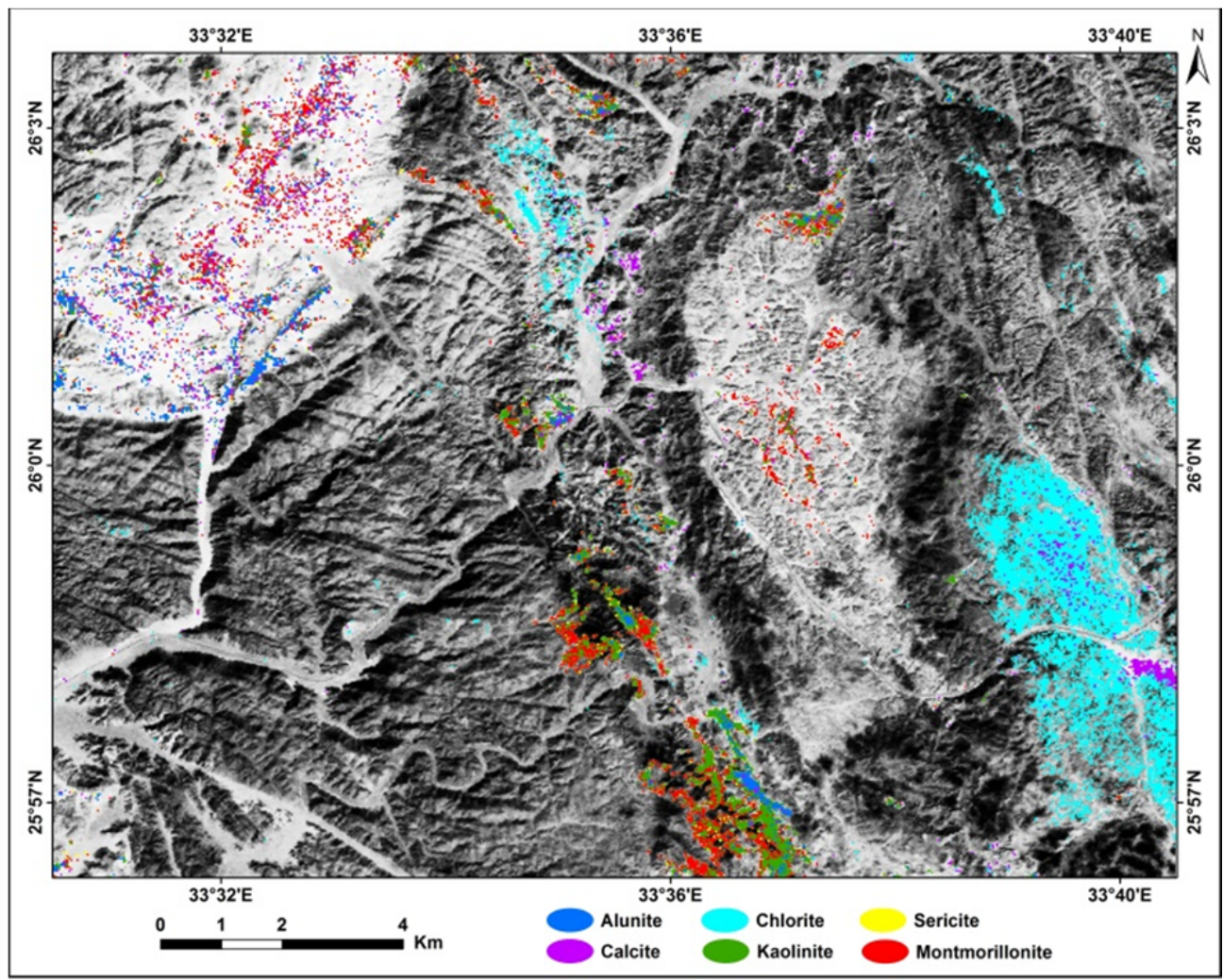


Application of remote sensing techniques on aster data

\section{Supervised classification of ASTER reflectance data}

The alteration zones in the study area were mapped from the ASTER reflectance data based on user defined reference spectra, the supervised classification methods used are the Spectral Angle Mapper (SAM) and Spectral Information Divergence (SID) techniques.

\section{Spectral Angle Mapper (SAM) Classification}

SAM is a physically-based spectral classification technique that uses an n-D angle to match pixels to reference spectra (endmembers). It determines the spectral similarity between two spectra by calculating the angle between the spectra and treating them as vectors in a space with dimensionality equal to the number of bands. We used the reference spectra (endmembers) of the same six alteration minerals used in the CEM technique. SAM compares image spectra to the user defined spectra (Kruse et al., 1993) in n-D space. Smaller angles represent closer matches to the reference spectrum. Pixels further away than the specified maximum angle threshold in radians are not classified.

The SAM results indicated that the dominant minerals are montmorillonite (red color), kaolinite (green color), alunite (blue color) and calcite (pink color) in the rocks of granite, serpentinite and the mélange rocks, while sericite (yellow color) dominates in the Dokhan Volcanics and chlorite (cyan color) dominates in metagabbros and in some locations of felsites (Fig. 11).

\section{Spectral Information Divergence (SID)}

Spectral Information Divergence (SID) is a spectral classification method that uses a divergence measure to match pixels to reference spectra. The smaller the divergence, the more likely the pixels are similar. Pixels with a measurement greater than the specified maximum divergence threshold are not classified. Endmember spectra used in the SID classification method are those of the USGS spectral library used in the CEM and SAM.

The maximum divergence threshold was tested by assigning different values for each alteration mineral to get the best classification results. The SID results indicated that the dominant minerals are sericite (yellow color), montmorillonite (red color), kaolinite (green color), alunite (blue color) and calcite (pink color) in the rocks of granite, serpentinite, Dokhan Volcanics, felsites and in some locations of metagabbro and Hammamat molasse sediments (Fig. 12).

Fig. 11:SAM Supervised classification technique using resampled USGS spectral signatures overlying ASTER band 6.

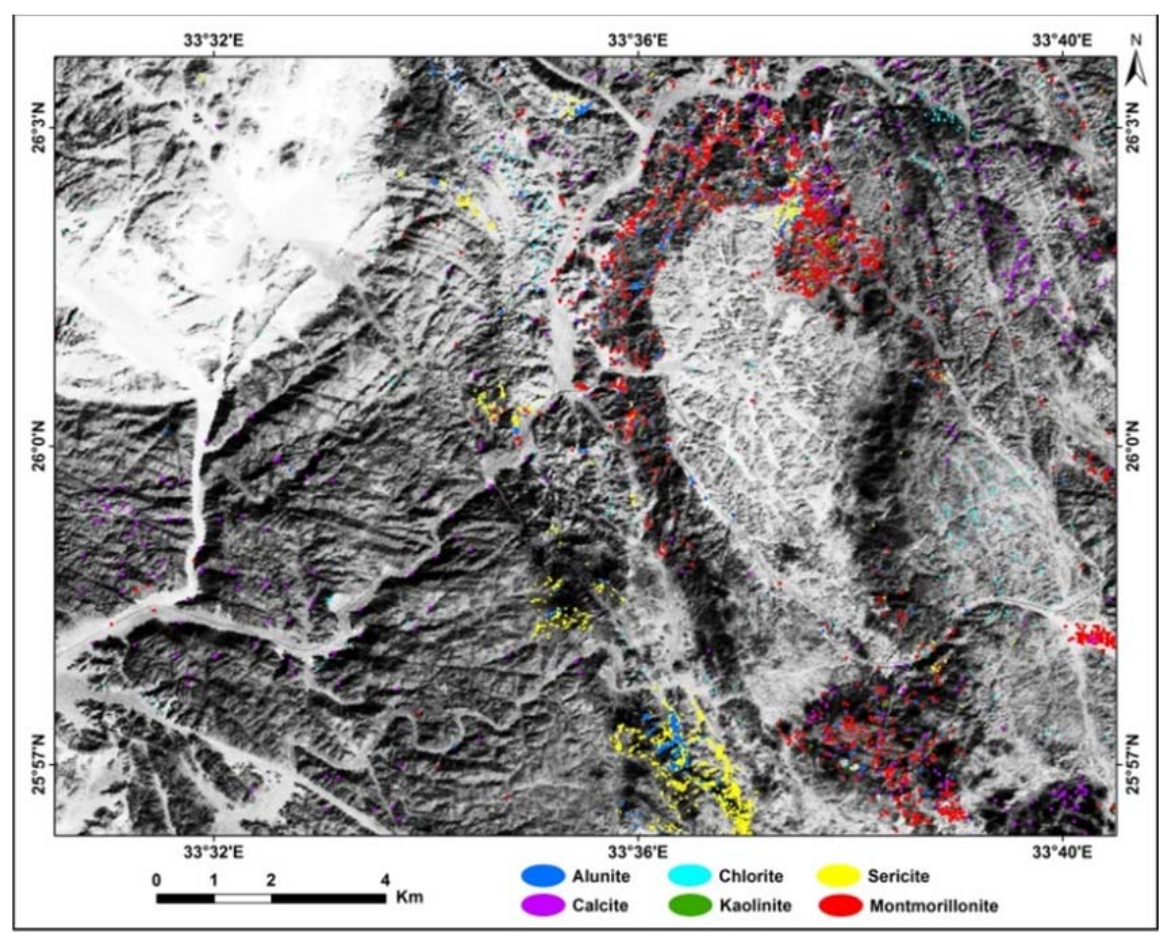


Ghoneim, et al.

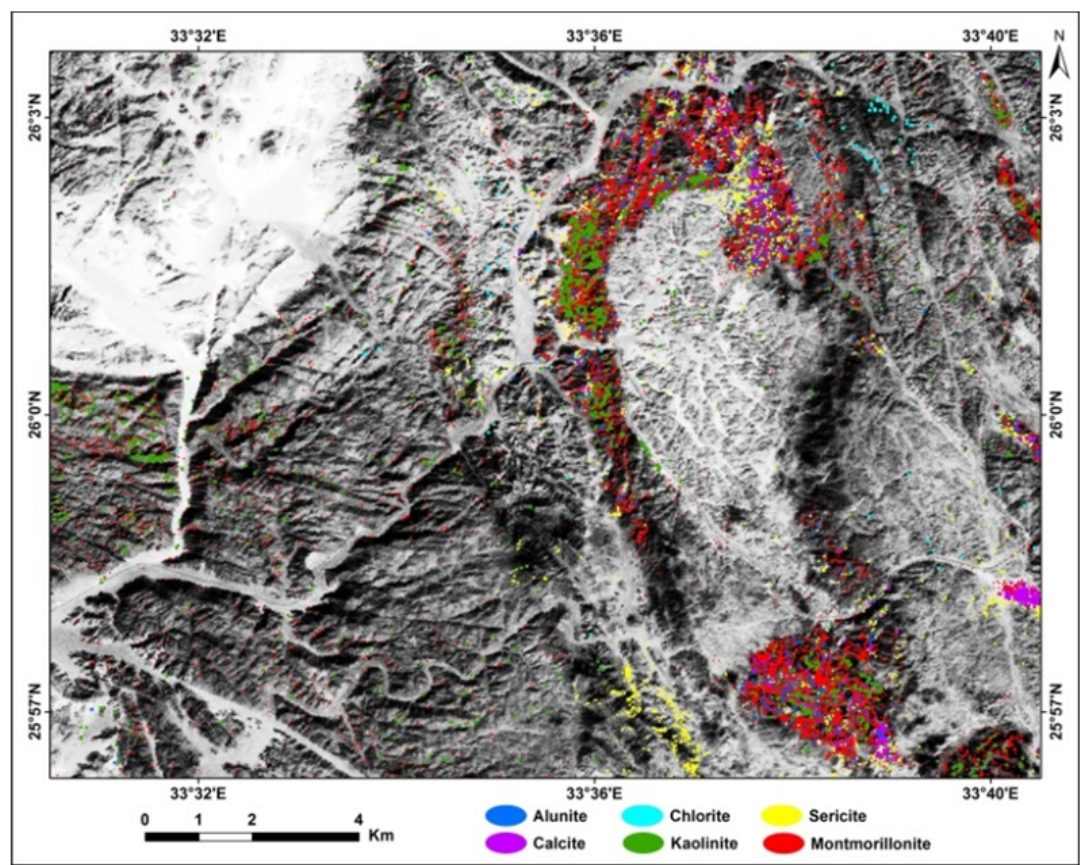

Fig. 12: SID Supervised classification technique using resampled USGS spectral signatures overlying ASTER band 6.

The comparison between the SAM and SID classifications indicated that:

i. The alteration zones have the same locations in SAM and SID classifications.

ii. Montmorillonite is dominant in SID classification whereas sericite shares the dominancy with montmorillonite in SAM classification.

iii. Kaolinite is well determined by the SID classification and slightly appeared in the SAM classification. iv. The absence of alteration minerals in wadi deposits in both SAM and SID classifications.

\section{Lineament extraction and relationship to gold mineralization}

A lineament is a mappable linear or curvilinear feature of a surface whose parts align in a straight or slightly curving relationship. They may be an expression of a fault or other line weakness (Hung et al., 2005). Satellite remotely sensed data has been widely used as source of information for geologists to map lineaments.

\section{Lineament extraction from ASTER imagery}

Identification of lineaments from satellite images can be achieved effectively by using two techniques: 1) Visual interpretation, lineaments have been visually detected using image enhancement techniques (image ratio, image fusion, directional edge-detection filters) and a lineament vector map can be produced using manual digitizing techniques (Arlegui and Soriano, 1998; Suzen and Toprak, 1998). 2) Auto detection, a lineament map is produced using computer softwares and algorithms (Burdick and Speirer 1980, Karnieli et al., 1996; Baumgartner et al. 1999, Hung et al. 2002, 2003, Kim et al. 2004).

In the present study, automatic lineaments extraction have been carried out using the most widely used software for such purpose (the LINE module of the PCI Geomatica package using the default parameters with adjustment of the Edge gradient threshold to 40 pixels). The algorithm of extraction consist of edge detection, thresholding and linear extraction steps. After testing the data, the best band for automatic lineament extraction was the First principal component band (PC1). Higher resolution imagery results in higher quality of lineament map (Hung et al., 2005). On this basis the PC1 is fused to get higher spatial resolution $(15 \mathrm{~m})$. The visual inspections of the extracted lineaments have been carried out for editing and eliminating the false (incorrect) lineaments such as roads, routs, buildings and any manmade features. The automatically extracted lineaments are shown in (Fig. 13) after being edited for elimination of the manmade features. 
Application of remote sensing techniques on aster data

\section{Lineaments Density}

Lineaments are commonly analyzed using lineament density maps (Zakir et al., 1999). In this research we calculated lineament density (Fig. 14) automatically using the Arc GIS v. 10.3 software on basis of the number of lineaments per unit area (number $/ \mathrm{km}^{2}$ ). Then the resultant lineament density map is contoured using the same software, in the lineament contouring map (Fig. 15) higher densities are represented by red color and they are assumed to represent a higher level of fracturization of the rock that is considered to have relation to the degree of mineralization.

Fig. 13: Automatically extracted lineaments from the ASTER image using PCI geomatica software.
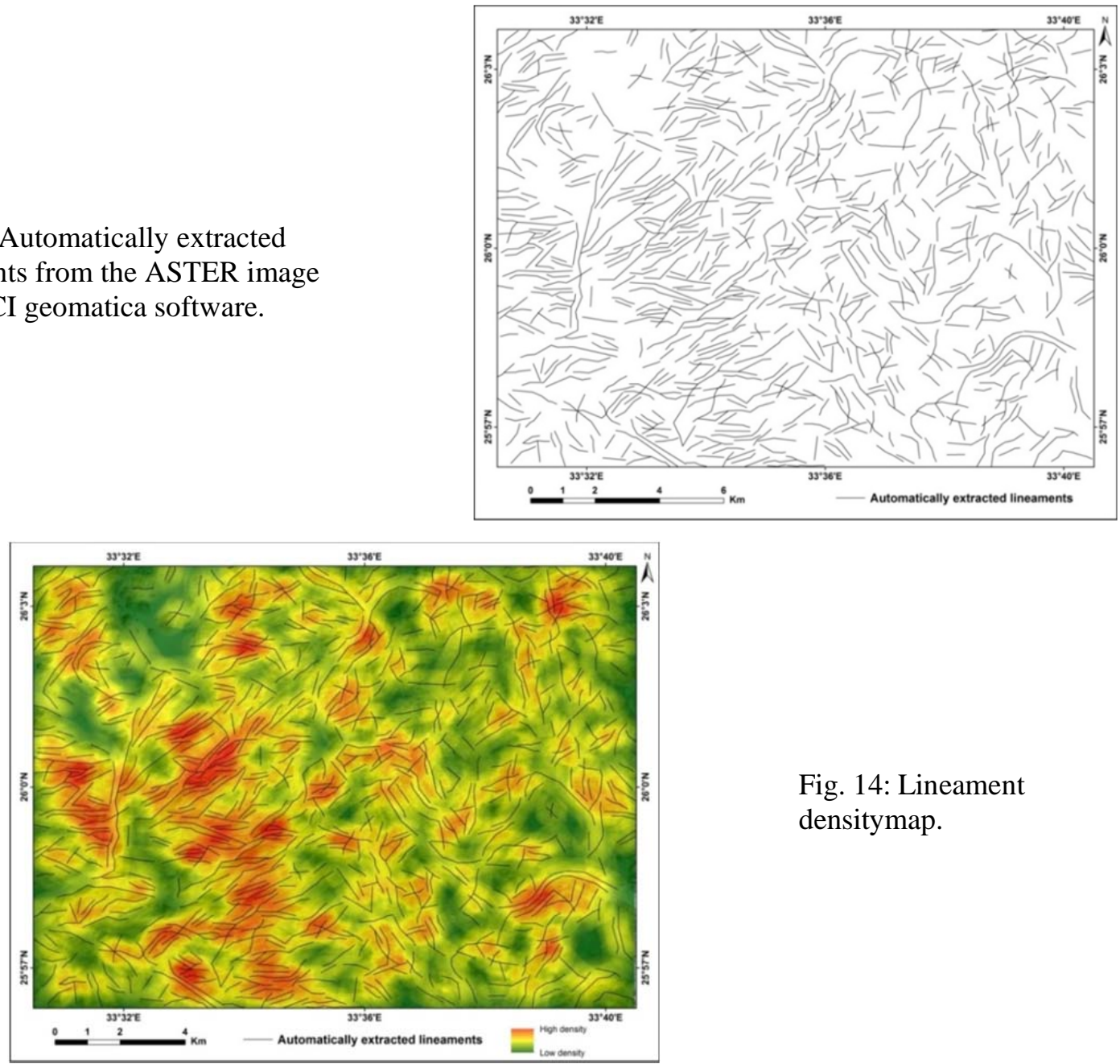

Fig. 14: Lineament densitymap.

Fig. 15: Lineament contouringmap,higher densities are represented byredcolor.

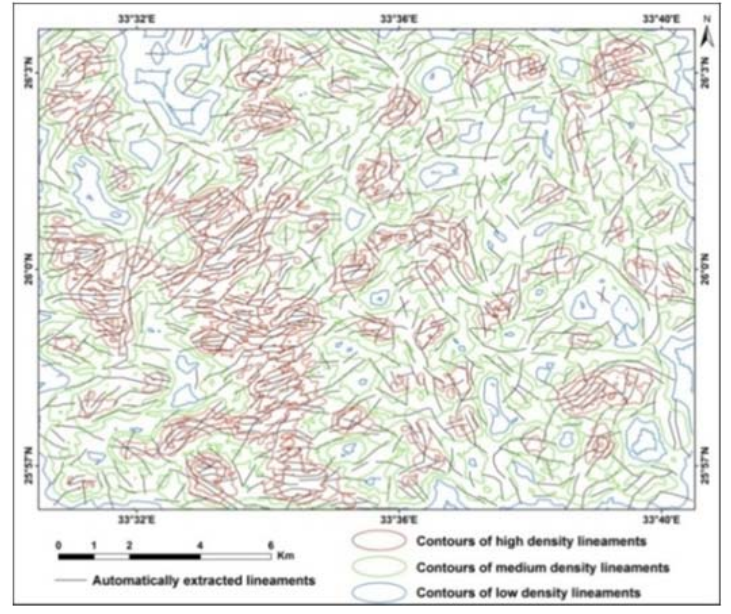


Ghoneim, et al.

Lineaments are zones of deformation and fracturing, which implies that they are zones of higher secondary porosity. As these zones become significant channel-ways for migration of fluids (Gupta, 2003). So the coincidence of high density lineaments and alteration zones indicate high probability for the presence of gold mineralization. Hence, the lineament density map will be more useful when it is combined with other information regarding the alteration zones in the area which have been successfully mapped using several approaches.

Overlying the locations of the old gold mines in the study area validates the results; we found that there is a complete harmony between the sites where the old gold mines in the area of study were already opened and the areas where the alteration minerals are present along with high lineaments density (Fig. 16).

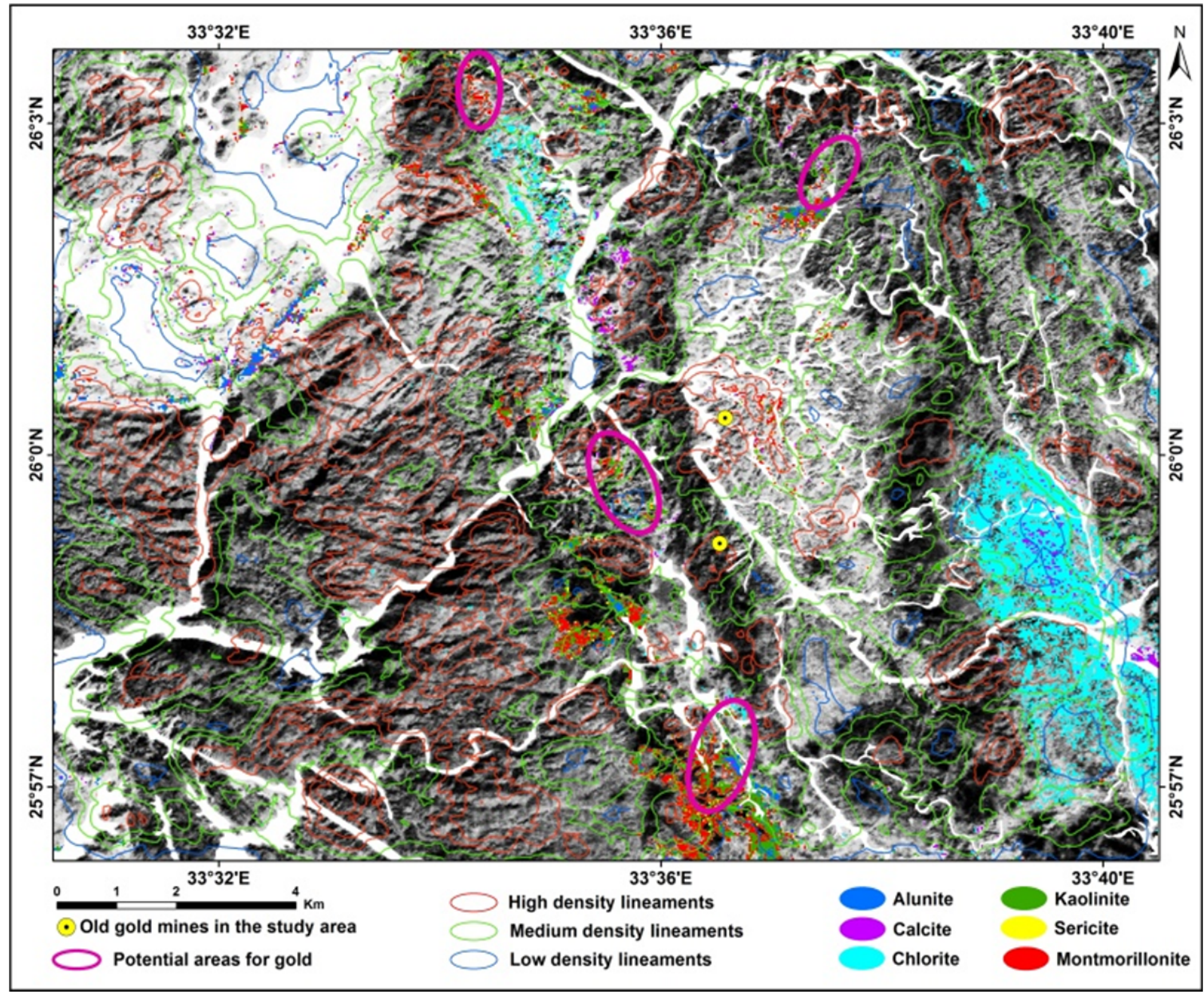

Fig. 16: Lineaments density contour and old mines locations overlying the CEM technique, higherdensities are represented byredcolor, all the layers are overlying ASTER band 6 .

\section{CONCLUSION}

Several criteria were carried out in this study including lithology, lineaments density and alteration zones. These criteria were prepared using different remote sensing techniques including False Color Composites (FCC), Color Ratio Composites (CRC) and Principal Component Analysis (PCA) for delineating the lithological units in the study area. While, the spectral ratio indices, Constrained Energy Minimization (CEM), Spectral Angle Mapper (SAM) and Spectral Information Divergence (SID) were used effictively for alteration zone extraction. CEM, SAM and SID gave successful results in the separation of the alteration zones through detecting the alteration minerals (Kaolinite, Alunite, Montmorillonite, Chlorite, Calcite and Sericite) and locating the spatial distribution of them in the study 
Application of remote sensing techniques on aster data

area. These alteration zones represent the highest important factor in this study. The final alteration map is integrated with the automatically extracted lineaments along with the locations of the old mines in the study area; these factors were integrated to define the potential areas for gold mineralizationOn the basis of presence of alteration minerals in areas with high lineaments density in suitable rock units, four potential areas for gold exploration have been proposed (Fig. 16). Abu El-Magd et al., 2015 used the same techniques for the eastern part of the study area and concluded that there are two potential areas for gold exploration, in this study, two more new probable areas for gold exploration have been introduced (Fig. 16). Concerning the western part which is occupied mainly by the Hammamat molasse sediments and Abu Had granitic intrusion there are no potential areas for gold exploration.

\section{REFERENCES}

Abdeen M. M., Allison T. K., Abdelsalam M. G. and Stern R. J., (2001): Application of ASTER bandratio images for geological mapping in arid regions; the Neoproterozoic Allaqi Suture, Egypt. Abstract with Program Geol. Soc. America, 3(3) 289.

Abdelsalam M. G., Stern R. J. and Berhane W. G., (2000): Mapping gossans in arid regions with Landsat TM and SIR-C images: the Beddaho alteration zone in northern Eritrea. J. Afr. Earth Sci., 30(4) 903916.

Abou El-Magd I., Mohy H. and Basta F., (2015): Application of remote sensing for gold exploration in the Fawakhir area, Central Eastern Desert of Egypt, Arab J Geosci DOI 10.1007/s12517-014-1429-4

Abrams M. J., Brown D., Lepley L. and Sadowski R., (1983): Remote sensing for porphyry copper deposits in southern Arizona. Economic Geology 78, 591- 604.

Amer R. M., Kusky T.M. and Ghulam A., (2010): Lithological mapping in the Central Eastern Desert of Egypt using ASTER data. J. Afr. Earth Sci. 56, 75-82.

Arlegui L. E. and Soriano M. A., (1998): Characterizing lineaments from satellite images and field studies in the central Ebro basin (NE Spain), Int. J. Remote Sensing 19 (16), 3169-3185.

Baumgartner A., Steger C., Mayer Eckstein W. and Ebner H., (1999): Automatic road extraction based on multi-scale grouping and context, Photogrametric Engineering and Remote Sensing, 65, 777-785.

Brandmeier M., (2010): Remote sensing of Carhuarazo volcanic complex using ASTER imagery in Southern Peru to detect alteration zones and volcanic structures-a combined approach of image processing in ENVI and ArcGIS/ArcScene, Geocarto International, 25(8) 629-648.

Burdick R. G. and Speirer R. A., (1980): Development of a method to detect geologic faults and other linear features from LANDSAT images, U. S. Bureau of Mines Report Inv., 8413:74.

Chavez P. S., Berlin G. L. and Sowers L. B., (1982): Statistical method for selecting Landsat MSS ratios. Journal of Applied Photographic Engineering, 8, 23-30.

Chavez P. S., Guptill S. C. and Bowell J. A., (1984): Image processing techniques for thematic mapper data. Proc. ASPRS-ACSM Tech. Paper, 2, 728-742.

Chica-Olmo M., Abarca F. and Rigol J., (2002): Development of a Decision Support System based on remote sensing and GIS techniques for gold-rich area identification in SE Spain, International Journal of Remote Sensing, 23(22) 4801-4814.

Drury S. A., (1993): Image interpretation in geology. 2nd ed., Champan and Hall, London, 283.

El Gaby S., List F. K. and Tehrani R., (1988): Geology, evolution and metallogenesis of the Pan-African belt of Egypt. In: El Gaby, S. and Greiling, R.O. (eds.), The Pan-African belt of northeast Africa and adjacent areas. Frieder. Vieweg and Sohn, Braunschweig, 17-68.

El Ramly M. F., Ivanov S. S., Kochin G. G., Bassyouni EA., Abdel Aziz A. T., Shalaby I. M. and El Hammady M. Y. (1970): The occurrence of gold in the Eastern Desert of Egypt. In: Studies on some mineral deposits of Egypt (Edited by Moharram O., Gachechiladze D.Z., El Ramly M.F., Ivanov S.S. and Amer A.F.), Part I, Section A, Geol. Sur. Egypt, 53-64.

Gabr S., Ghulam A. and Kusky T. (2010): Detecting areas of high-potential gold mineralization using ASTER data. Ore Geology Reviews, 38, 59-69.

Gad S. and Kusky T., (2007): ASTER spectral ratioing for lithological mapping in the Arabian-Nubian shield, the Neoproterozoic Wadi Kid area, Sinai, Egypt. Gondwana Research, 11(3) 326-335. 
Ghoneim, et al.

Garson M.S. and Shalaby I.M., (1976): Precambrian-lower Paleozoic plate tectonics and metallogenesis in the Red Sea region. Geol. Ass. Canada, Spec. Paper 14, 573-596.

Geo-Referencing ASTER Level-1B Data, (March 31, 2006): General Overview and Examples of Particular COTS Packages and Public Domain Software, https://lpdaac.usgs.gov/sites/default/files/public/aster/docs/ASTER GeoRef FINAL.pdf

Greiling R. O., de Wall H., Sadek M. F. and Dietl C., (2014): Late Pan-African granite emplacement during regional deformation, evidence from magnetic fabric and structural studies in the HammamatAtalla area, Central Eastern Desert of Egypt, J. Afr. Earth Sci. 99,109-121

Gupta R. P., (2003): Remote Sensing Geology, $2^{\text {nd }}$ Edition. Springer, India. 656.

Hume W. F., (1937): Geology of Egypt, vol. II. The Fundamental Precambrian Rocks of Egypt and the Sudan, their distribution, age and character, Part III, The Minerals of Economic value. Geol. Sur. Egypt, Cairo, 300.

Hung L. Q., Batelaan O. and De Smedt F., (2005): Lineament extraction and analysis, comparison of Landsat ETM and ASTER imagery. Case study: Suoimuoi tropical karst catchment, Vietnam, Remote Sensing for Environmental Monitoring, GIS Applications, and Geology, 15, 59830T-12.

Hung L. Q., Batelaan O. and San D. N., (2003): Lineament analysis in fractured rocks, methodology and application to the Suoimuoi karst catchment (full paper on CD). Proc. Int. Conf. Groundwater in Fractured Rocks, 15-19.

Hung L. Q., Dinh N. Q., Batelaan O., Tam V. T. and Lagrou D., (2002): Remote sensing and GIS-based analysis of cave development in the Suoimuoi catchment (Son La- NW Vietnam), Journal of Cave and Karst Studies, 64(1):23-33.

Karnieli A., Meisels A., Fisher L. and Arkin Y., (1996): Automatic extraction and evaluation of geological linear features from digital remote sensing data using a Hough transform, Photogrammetric Engineering and Remote Sensing, 62(5) 525-531.

Kim G. B., Lee J. Y. and Lee K. K., (2004): Construction of lineament maps related to groundwater occurrence with Arcview and AvenueTM scripts, Computers and Geosciences, 30, 1117-1126.

Kruse F. A., Lefkoff A. B., Boardman J.B., Heidebrecht K. B., Shapiro A. T., Barloon P.J. and Goetz A.F., (1993): The Spectral Image Processing System (SIPS) Interactive Visualization and Analysis of Imaging Spectrometer Data. Remote Sensing of the Environment 44, 145-163.

Mohy, H. (2014): Application of remote sensing for gold exploration in the fawakhir area, central Eastern Desert of Egypt. M. Sc. Thesis, Cairo Univ.

Ninomiya Y., (2003): A stabilized vegetation index and several mineralogic indices defined for ASTER VNIR and SWIR data. Proceedings of IEEE International Geoscience and Remote Sensing Symposium. IGARSS'03, 3, 1552-1554.

Pascal's Triangle and the ice cream cones, (Dec. 9, 1994): mathforum.org/library/drmath/view/59185.html

Qaid M. A. and Basavarajappa T.H., (2008): Application of Optimum Index Factor Technique to Landsat-7 Data for Geological Mapping of North East of Hajjah, Yemen. American-Eurasian Journal of Scientific Research. 3, 84-91.

Sabet A. H., Tosgoev V. B., Bordonosov V. P., Babourin L. M., Zalata A. A. and Francis M. H. (1976): On gold mineralization in Eastern Desert, Egypt. Ann. Geol. Sur. Egypt, 6, 201-212.

Sabins F. F., (1997): Remote Sensing principles and interpretation. W. H. Freeman Company, New York: 366-371.

Salem S. M., (2013): Detecting of new alteration zones for gold exploration at the Barramiya District, Central Eastern Desert of Egypt using ASTER data and geological field verification, Arabian Journal of Geosciences, AJGS-D-12-00632.

Schowengerdt R. A., (2007): Remote Sensing: Models and Methods for Image Processing ( $3^{\text {rd }}$. ed.), Academic Press, San Diego, USA.

Sultan M. and Arvidson R .E., (1986): Mapping of serpentinites in the Eastern Desert of Egypt by using Landsat Thematic Mapper data. J. Geol., 14(12): 995-999.

Süzen M.L. and Toprak V., (1998): Filtering of Satellite Images in geological lineament analyses: An application to a fault zone in Central Turkey, Int. J. Remote Sensing, 19(19), 1101-1114.

Zakir F., Qari M. and Mostfa M., (1999): A new optimising technique for preparing lineament density maps, Int. J. Remote Sensing, 20, 1073-1085. 